\title{
Copper Cu 64 TP3805
}

National Cancer Institute

\section{Source}

National Cancer Institute. Copper Cu 64 TP3805. NCI Thesaurus. Code C98289.

A peptide analog of pituitary adenylate cyclase-activating peptide (PACAP) radiolabeled with the positron-emitting radioisotope copper Cu 64, with potential diagnostic ability upon positron emission tomography (PET) imaging. The peptide moiety of copper Cu 64 TP3805 is able to bind to vasoactive intestinal peptide/pituitary adenylate cyclase activating peptide receptors 1 (VPAC1). Upon PET imaging, the cancer cells expressing VPAC1 can be visualized and may allow for early detection. The oncogenic product VPAC1 is overexpressed in a variety of cancer cell types, moreover, it is overexpressed in $100 \%$ of breast tumors at the onset of the cancer. Compared to other positron-emitting radioisotopes, Cu 64 has a longer half life. 